Article

\title{
What Ecosystem Services Flowing from Linpan System-A Cultural Landscape in Chengdu Plain, Southwest China
}

\author{
Shuang $\mathrm{Wu}^{1}{ }^{1}$, Ning $\mathrm{Wu}^{2, *}$ and Bo Zhong ${ }^{2,3}$ (1) \\ 1 Built Environment, University of Washington, Seattle, WA 98195, USA; shuangw1@uw.edu \\ 2 CAS Key Laboratory of Mountain Ecological Restoration and Bioresource Utilization \& Ecological \\ Restoration and Biodiversity Conservation Key Laboratory of Sichuan Province, \\ Chengdu Institute of Biology, Chinese Academy of Sciences, Chengdu 610041, China; zhongbo@cib.ac.cn \\ 3 Chengdu Branch, University of Chinese Academy of Sciences, Beijing 100049, China \\ * Correspondence: wuning@cib.ac.cn; Tel.: +86-28-82890993
}

Received: 3 March 2020; Accepted: 16 May 2020; Published: 18 May 2020

\begin{abstract}
As an ecosystem complex integrated with functions of agricultural production, residence, and socio-cultural activity, linpan (wooded lot) has characterized socio-ecologically and culturally the rural landscape in Chengdu Plain. Although functioning for centuries without disruption and supporting continuously the regional prosperity, it is currently under big threats due to rapid urbanization and a growing population. The overall goal of this paper is to improve our understanding of the linpan system and its services. Within the framework of four categories of ecosystem services, including provisioning, regulating, cultural and supporting services, the deliverables by linpan were elaborated respectively based on document review and field survey. It was addressed that as a localized cultural landscape, linpan has and will continue to provide various services to rural as well as urban people. These services including material and non-material values were highly recognized by local people, but the perceived importance of services were changeable with the socio-economic development, market fluctuation, and people's awareness rise. Regarding the preservation of the linpan system as an important agricultural heritage system, cultural services should not be neglected within a landscape management framework. Finally, this study called for attention to the dynamics of the linpan system which required an adaptive approach for assessing and managing ecosystem services.
\end{abstract}

Keywords: Linpan; Chengdu Plain; ecosystem services; cultural landscape; important agricultural heritage system

\section{Introduction}

China's rapid urbanization fueled by the economic boom of the last three decades has transformed an agrarian society in many parts of China into an urbanized one at such a short time and large scale [1,2]. It is an unprecedented event in human history, which has attracted the world's attention of scholars from different disciplines [3-7]. What is less known is how this drastic change sweeping across the countryside has influenced the rural landscape and its ability to provide ecosystem services to both rural and urban areas. Urban-rural linkages reflected economic transformations in the process of urbanization and formed a complex web of connections [8]. Driven by the forces of urbanization, a competitive relationship occurs between urban and rural systems, which may result in resource competition and weaken the resilience of both urban and rural areas [8-10]. Due to the newly reshaped human-environment interactions between urban-rural interfaces, the functionalities of rural and peri-urban areas in ecosystem services have received increasing concerns [11,12]. 
The linpan (wooded lot) system is a kind of agricultural or cultural landscape scattered from peri-urban to rural areas in Chengdu Plain, southwest China. It has been used as the residential cluster by local people for hundreds or even thousands of years and has continued to be the main residential dwellings of Chengdu's farmers $[13,14]$. Recent studies illustrated that linpan's functions include not only residential but also agriculturally productive, socio-ecological, and even cultural $[15,16]$, which thus need a comprehensive understanding of a socio-ecological system approach. However, with the rapid urbanization recently in Chengdu Plain, this landscape is under threat and even disappearing $[4,17]$. In some administrative villages (called xing zheng cun in Chinese) and townships (called xiang in Chinese) nearby Chengdu city, the traditional residential clusters have been replaced by a centralized urban model which was driven by so-called "Three Concentrations Policy", (the concentration of industries in development zones, the concentration of rural population in urbanizing township, and the concentration of land for scale operation by enterprises) $[14,18,19]$, although this process is being slowed down recently. As an important metropolis in Southwest China, Chengdu has piloted a national initiative of urban-rural integration development since 2003 and then been promoted in 2007, with Chongqing (another metropolis about $300 \mathrm{~km}$ to the east) as a dual-core city cluster $[4,18]$. This urbanization process was later accelerated by the disaster recovery after the Wenchuan earthquake in 2008 [20]. However, after the earthquake, the government realized the self-supportive model of rural life can be resistant to hazards, and thus dispersal dwellings were developed accordingly.

This rapidly urbanizing process in rural Chengdu has attracted many scholars and policymakers to study the direct and indirect drivers of socio-ecological changes and their intricate interactions. A lot of attention was paid to the trend of development and the influence on land cover change $[4,18,21]$, urban growth and land-use outcomes [22], and their implication to socio-cultural and aesthetic values [14], urbanism theory and urbanization influence [23,24]. Shu et al. (2013) [17] analyzed the impacts of land consolidation on farmers' traditional settlements in the Chengdu Plain and tried to explore the approach to integrate traditional architectural elements into the new rural design. Later, Tippins (2014) [25] evaluated the resilience of the linpan landscape using case studies in Pixian County (now called Pidu District) under the redevelopment alternatives and focuses specifically on landscape structure (spatial pattern) as variables in agro-ecosystem resilience. Recently, Whiting et al. (2019) [10] analyzed the historic resilience of rural landscape in Chengdu Plain in considering a set of ecological, governance, and market factors and discussed how their changes currently have threatened the sustainability of linpan system as well as the agrarian society as a whole. Regarding the linpan as a functioning socio-ecological system, a few reports analyzed the structure and biodiversity of the linpan system [26] and discussed the relationship between residential clusters and the environment in philosophical senses such as the thought of 'harmony between the heaven and human' from Daoism [15,16,27]. With the increasing acknowledgment of the importance of the linpan landscape by researchers, designers, and even policymakers, the local government of Pidu District proposed in 2017 to nominate this agricultural landscape as the National Important Agricultural Heritage Systems (NIAHS), which was finally approved by the national government in 2019.

Ecosystem services provided by natural and semi-natural systems are fundamental to people's survival and lives [28]. It was found that smallholder farmers are particularly vulnerable as they are highly dependent on natural resources for their livelihoods [29]. Agricultural production as well as household food security, income, and well-being of the rural population are impacted directly by the change of rural environment and the services due to climate change and human disturbances including urbanization [30]. Good management of the agricultural ecosystem for sustainably delivering goods and services could contribute to the daily needs of local farmers and long term benefits such as the overall adaptation strategy at the regional and national levels [29,30]. However, in terms of ecosystem services study, most attentions of previous studies were paid to biophysical assessments of ecosystems to deliver services [31-33], or to the economic value of ecosystem services [34,35]. Only a few considerations have focused on the non-material values from the perspective of human attitudes, beliefs, and motivations [36]. Thus, in the last ten years, some scholars emphasized the 
importance to link ecosystem services with cultural landscape research [37], adopted social preferences for non-economic evaluation of ecosystem services [38], and unraveled those values that tend to be obscured by monetary languages [39]. Moreover, along the urban-rural gradient, most of the ecosystem services presented divergent in their spatial patterns due to the difference in the urbanization process in different cities [40]. For the case of Chengdu, comprehensively understanding and assessing the ecosystem services of its traditional rural landscape which has been less disturbed or not been destructed by the currently urbanizing process is necessary for integrative planning and adaptive management of the cultural landscape in the future.

Among the targets of Sustainable Development Goals of United Nations, one target of SDG 11 (Sustainable Cities and Communities) addressed especially to "support positive economic, social and environmental links between urban, peri-urban and rural areas by strengthening national and regional development planning" [41]. In order to support the sustainability of a city, its rural area could not be separated from the overall consideration in maintaining the flow of ecosystem services within the urban-rural context [42]. Linpan, without a doubt, is embedded in the linkage between the built environment in urban and rural nature, which is very important for sustaining ecosystem services to local farmers as well as urban people in Chengdu. However, it is still a lack of comprehensive study so far on the ecosystem services provided by the linpan system in Chengdu Plain, although there are a few cases discussed some specific services in previous studies $[43,44]$. Therefore, a study is conducted here, aiming at clarifying the contribution of rural landscape to deliver ecosystem services with the example of linpan, and further elucidating the importance of it as a vernacular landscape (different from the designed landscape) for sustainable development in Chengdu Plain.

\section{Materials and Methods}

\subsection{Study Sites}

In order to identify the representative features of linpan system, a field survey was carried out in two case-study sites, including Paotong Village in Pidu District, about $22 \mathrm{~km}$ to the west of Chengdu in 2017 and 2018, and Dantu Village in Tianfu District, about $20 \mathrm{~km}$ to the south of Chengdu in 2019 (Figure 1). The backgrounds of two case-study sites are described as follows.

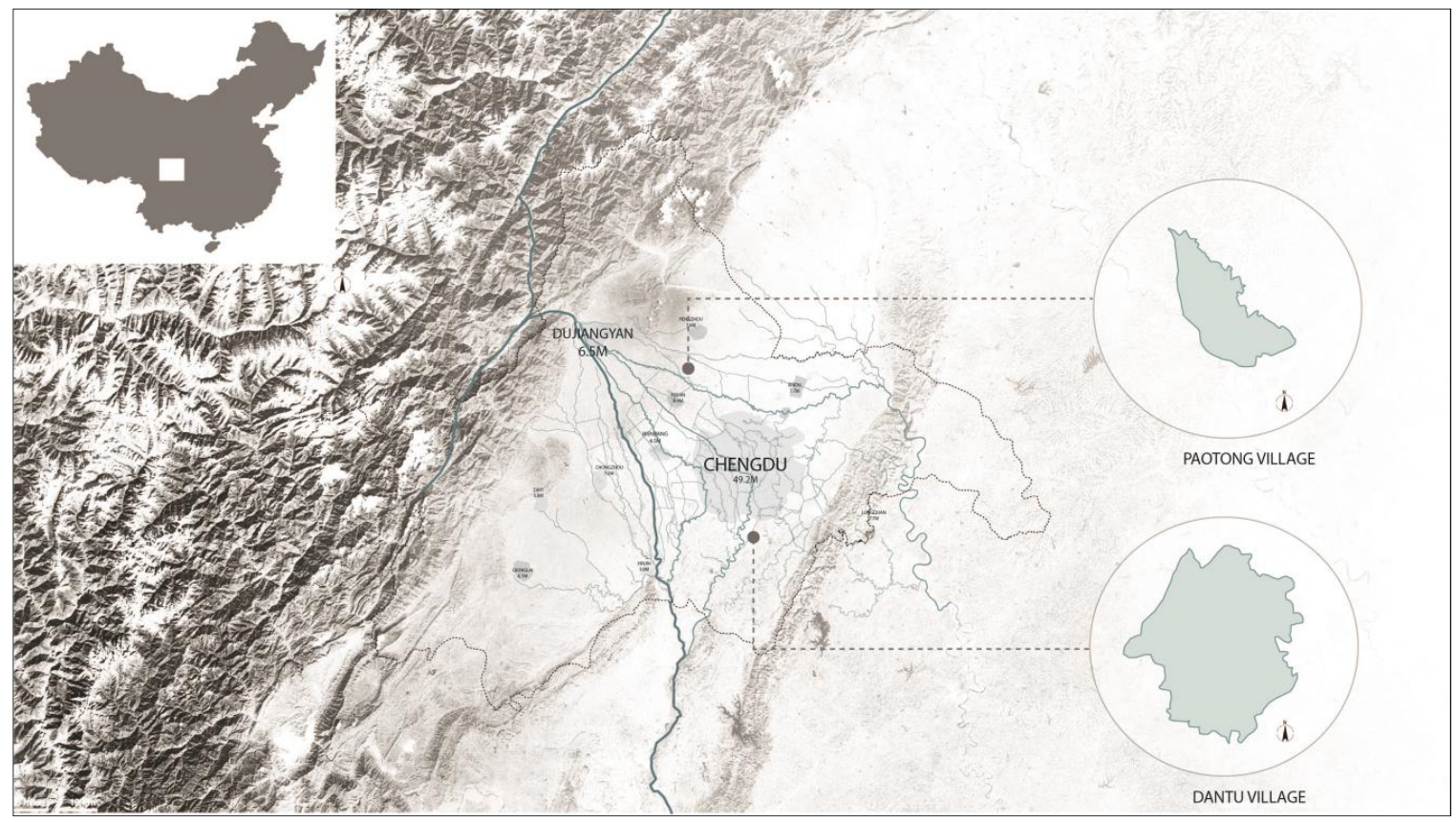

Figure 1. Location map showing case-study sites in Dujiangyan Irrigation System watershed, Chengdu Plain of China, including Paotong Village, Pidu District, and Dantu Village, Tianfu District. 
Paotong Village, Pidu District: This village with an area of $1.87 \mathrm{~km}^{2}$, and a population of $2290 \mathrm{in}$ 2018 is a typical agrarian area where local people traditionally engaged in crop cultivation. It belongs to the oldest part of Dujiangyan Irrigation System watershed with very flat topography and fertile soil. Recently this area has experienced rapidly urbanizing influence following with infrastructure development (such as second ring expressway) and livelihood transformation (such as rural tourism). Except for this village, linpan in other neighbors are losing a lot due to the planned construction of centralized settlements for farmers.

Dantu Village, Tianfu District, located to the south of Chengdu city with an area of $6.45 \mathrm{~km}^{2}$ and a population of 3212 in 2018, is a gently hilly and relatively low fertile area. The irrigation system (i.e., Dong Feng canal) connecting with the Dujiangyan Irrigation System was constructed in the 1950s and 1960s. Now Dantu Village is an administrative village with a traditional rural market (called chang in Chinese). Local residents at the marketplace engage not only agricultural production but also periodic trading activities. Livelihoods of local farmers are diverse including cultivation, agroforestry, and newly occurred fish-farming.

\subsection{Survey Methods}

The overall goal of this paper is to improve our understanding of the linpan system and the plenty of services that the system provides to local people. A scoping study on current theories and arguments about the definition and geographical distribution of linpan was carried out to clarify a few vague concepts and highlight key messages. An extensive list of ecosystem services obtained and derived from these ecosystems was documented based on the literature review. These services were then categorized into provisioning, regulating, supporting, and cultural services, following the Millennium Ecosystem Assessment (2003) [45] framework.

The interviews were semi-structured around key topics to explore the knowledge, practices, and perceptions related to the sense of importance and level of dependency on ecosystem services. A structured questionnaire was prepared for learning respondents' perceptions about the importance of ecosystem services, including provisioning services, regulating services, and cultural services. At least two specific services were hoped to be selected in each category. While conducting the surveys, the term ecosystem service was always referred to as "the benefits that ecosystems provide for life and livelihood" to make the term more understandable. Considering the fourth category i.e., supporting services being too theoretical and a little bit vague for local people, it was not included in the questionnaire and investigated by authors mainly through field observation combining with literature review. In Paotong Village and Dantu Village, 40 and 50 in-depth interviews were carried out respectively with purposively selected smallholder farmers and key informants in considering the gender, age, and education balance. Their responses to the questionnaire about the importance of ecosystem services were calculated as the percentage of each service to illustrate their perceptions. Two group open discussions with village leaders including three current government officials (members of the village committee, young people, did not participate in the questionnaire survey) and two retired members (old people, included in the questionnaire survey as key informants) were organized by authors separately in Dantu Village and Paotong Village to learn the implementation of policies and the governance system related to landscape conservation and socio-economic development, which were hoped to enhance our understanding on the status and trend of the services delivered by local ecosystems.

A field investigation was carried out for identifying environmental and socio-economic factors (e.g., climate, water resource, hydraulic system, transportation condition, and marketing activities, etc.), landscape heterogeneity, and biodiversity. Satellite images and drone photography were used to capture the major features in land use, settlement cluster morphology and landscape pattern in case-study areas to substantiate the information. Geospatial tools (i.e., ArcGIS) [46] were used to analyze the landscape configuration and visualize the findings. Landscape metrics such as linpan radius, base size, and density were calculated with computer-based software FRAGSTATS [47]. It should be noted that the characteristics and services discussed in this paper are focusing on the traditional linpan that is 
relatively well-protected. Those modernized or newly rebuilt linpan, such as the centralized residences or small townships rebuilt by governments for tourism purposes were excluded in this discussion.

\subsection{Limpan's Definition}

The term "linpan" has been used widely as a local slang in Chengdu for hundreds of years and has become an identifier of the Chengdu Plain $[27,48]$. Generally, a single "linpan" or a "linpan unit" refers to a kind of settlement cluster distributed in the rural Chengdu Plain (or called Chengdu Basin), southwest China, which normally consists of a few farmers' houses or courtyards surrounded with trees/bamboo groves [43,49] (Figure 2). On the other, a "linpan system" or "linpan landscape" indicates a network composed by a lot of linpan units scattering on the agricultural landscape with farmlands (mostly rice paddy) around and linked morphologically by a hydraulic system (rivers, canals, ditches, and weirs) and transportation system (highway, roads, paths, and trials), which has become a type of cultural landscape. Linpan is also the representative of the agricultural culture in the Chengdu Plain integrating traditional production, residence, and daily life of local farmers $[16,50]$. This definition indicates that linpan is not only a farmers' dwelling but also a socio-ecological system, or called 'ecosystem complex'.

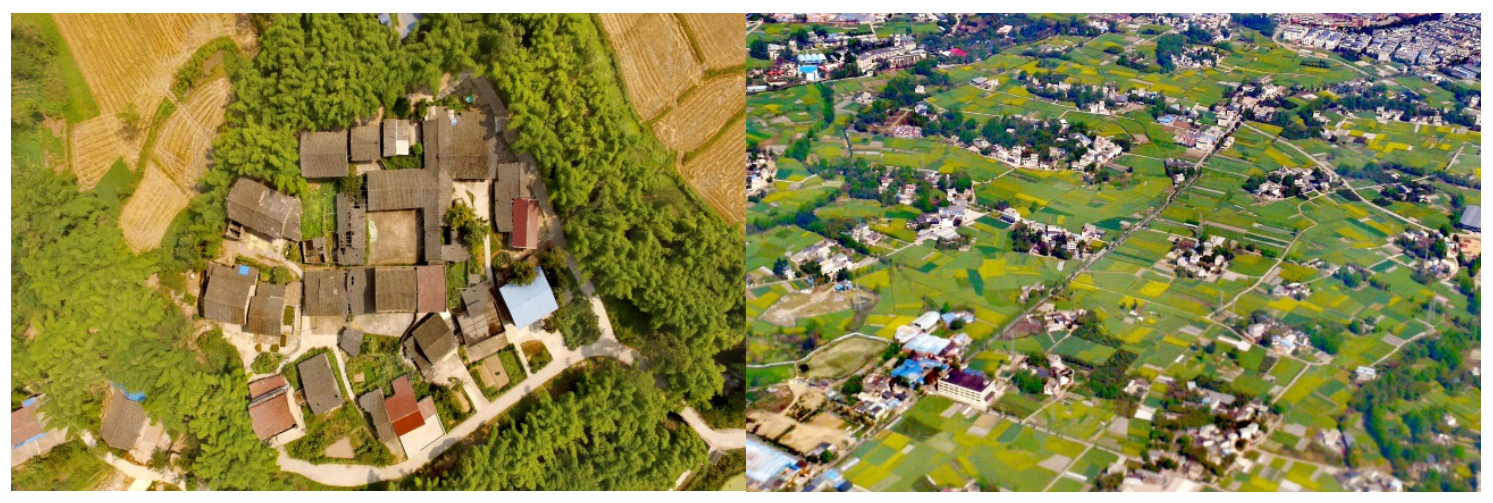

Figure 2. Drone photography showing linpan unit (left) and linpan landscape (right) in Chengdu Plain.

Recently scholars proposed many definitions about linpan (see review by Liu et al., 2017 [43]), but not one of them is widely accepted. $\mathrm{Li}$ (2009) [51] defined linpan from the perspective of landscape pattern and ecological structure as a kind of rural residence style, i.e., settlements with surrounding woodlands, streams and farmlands integrating with the natural environment and forming a green "island" embedded in the vast agricultural landscape. However, Duan and Liu (2004) [49] described linpan in a very romantic way, saying "walking on the Chengdu Plain, if you see a cluster of woods and bamboos with streams flowing inside, following the path you can find a farmhouse, and this is the location where linpan is." From a socio-cultural perspective, Chen (2011) [52] thought linpan, closely integrated with Dujiangyan Irrigation System, traditional agricultural activities and family relationships, is a living space that represents a certain ecological value and cultural features in rural west Sichuan. The concept proposed by Zhang (2008) [53] emphasized on the ecological features of linpan, describing it as "linpan community" (being analogous to a biological community), which indicates a settlement system distributed on semi-natural wetlands (rice paddy) of Dujiangyan watershed (Chengdu Basin). Generally, the argument is resulting from the divergence on an individual linpan and a (collective) linpan system, with some viewpoints only addressing the specific or one-sided functions of this socio-ecological system.

According to the above descriptions of linpan, we can find some commonalities among different definitions although different authors have their own understanding. No matter what definition is used, there is an implication that linpan is not a static object, but a living socio-ecological system that is both natural and cultural. Within a linpan (unit), there are four essential elements-farmers' houses in the middle, woodlands surrounding the houses and courtyards, farmlands extending nearby, and 
irrigation streams flowing through or passing by (Figure 3). In addition to roads, the connection within a linpan network is the hierarchy irrigation system [19]. We can use a landscape ecology model—patches (farmlands, wooded lots), corridors (roads and irrigation canals), and matrices (thousands of linpan units, hundreds of marketplaces, and/or small townships) to present a picture of linpan landscape.

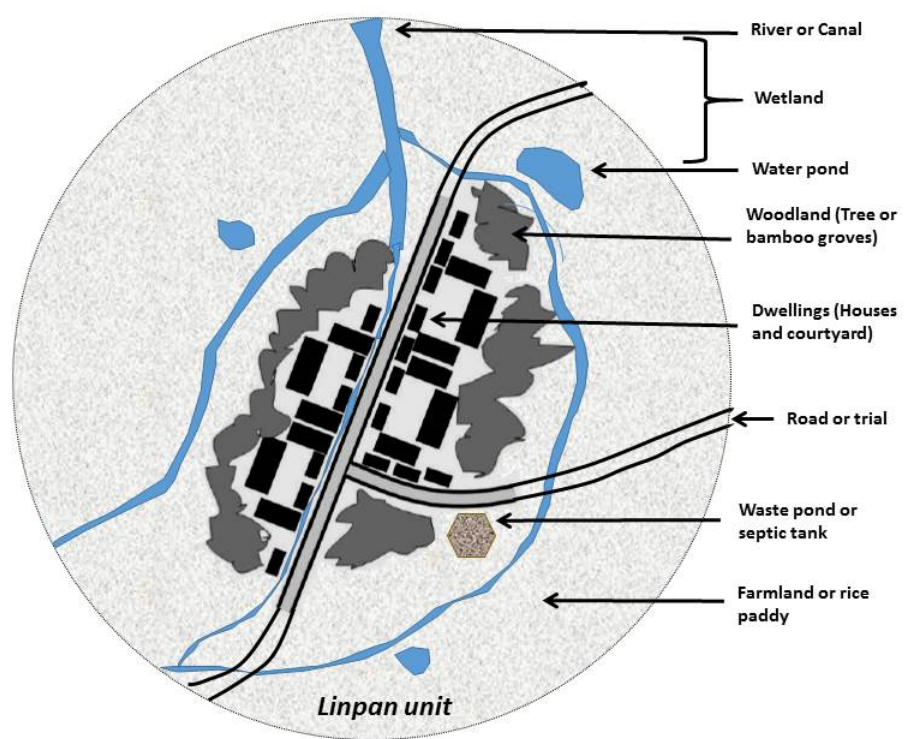

Figure 3. A schematic linpan unit showing major components.

\subsection{Geographical Pattern of Linpan}

Generally speaking, linpan is found mainly in Chengdu Plain, which is an alluvial basin located between $103^{\circ}-104^{\circ} 42^{\prime} \mathrm{E}$ longitude and $29^{\circ} 31^{\prime}-31^{\circ} 50^{\prime} \mathrm{N}$ latitude, about $110 \mathrm{~km}$ long from north to south and $80 \mathrm{~km}$ wide from west to east with an area about 7000 square kilometers [48] (Figure 1). The great Minjiang River, together with its tributaries, runs across the Chengdu Plain to form an expansive water network. With the elevation about 400-700 meters above sea level, the climate of this plain is typically subtropical with a mild temperature (annual mean temperature: $15.1-17.3^{\circ} \mathrm{C}$ ) and rich rainfall (annual precipitation: $880-1250 \mathrm{~mm}$ ) almost all year round, which provides ideal conditions for rice and vegetable cultivation, subtropical fruit plantation, and evergreen broadleaves trees (or bamboo) growing, becoming so-called 'The Land of Heavenly Abundance' (Tian Fu Zhi Guo in Chinese) in China [48,52].

Given the long-lasting, comprehensive, and large-scale human intervention (e.g., land use) in Chengdu Plain, almost its entire land surface can be considered a mosaic of cultural landscapes, in which different stages of anthropogenic influences have been overlaid and refined. Generally, the network of irrigation canals flowing down from the Dujiangyan Irrigation System, a world heritage site built around $256 \mathrm{BC}$, now is still operating in a much-expanded area of about $6700 \mathrm{~km}^{2}$ and influencing the morphology and configuration of the agricultural landscape $[15,16,19]$. In this landscape residential clusters (linpan) are linked with each other by irrigation system from which local people can access water sources conveniently for farming or daily use [54]. Many scholars thus considered that linpan was formed by the long-term interaction between human society and the environment in Chengdu Plain [55-59]. In order to prevent the damage of flash floods occasionally occurred in summer, for instance, farmers' dwellings are always located far away from the main canals (arterial channels) ( gan qu and dou qu in Chinese) but close to the small branches (capillary channels) (zhi qu and mao qu in Chinese) $[57,60]$.

Geospatial analysis indicated that the radius of a linpan unit is usually less than $300 \mathrm{~m}$ and the radius of agricultural activities (farming radius) of linpan's inhabitants (i.e., farmers) is around $1.5 \mathrm{~km}[60,61]$ or even shorter [27]. The radiuses reflect the balance of water demand and supply for 
the residents living in linpan dwellings. A short distance between linpan units (residential clusters) or a highly dense pattern means a high pressure on land use and water resource due to the dense population [25]. Therefore, a rational distance in between is necessary for maintaining the resilience of ecosystems within their thresholds. Based on the calculation with software FRAGSTATS, the interval distance between two near linpan is around 300-500 $\mathrm{m}$ in both of case-study villages (Figure 4; Table 1). Too wide space, on the contrary, implies inconvenience for farmers to manage their farmlands or management being too extensively [17]. In Chengdu Plain it was estimated that there were about 121,100 linpan units in 2014 and the population living in linpan was around 3.65 million, amounting to $72.4 \%$ of the total rural population in Chengdu [43,48].

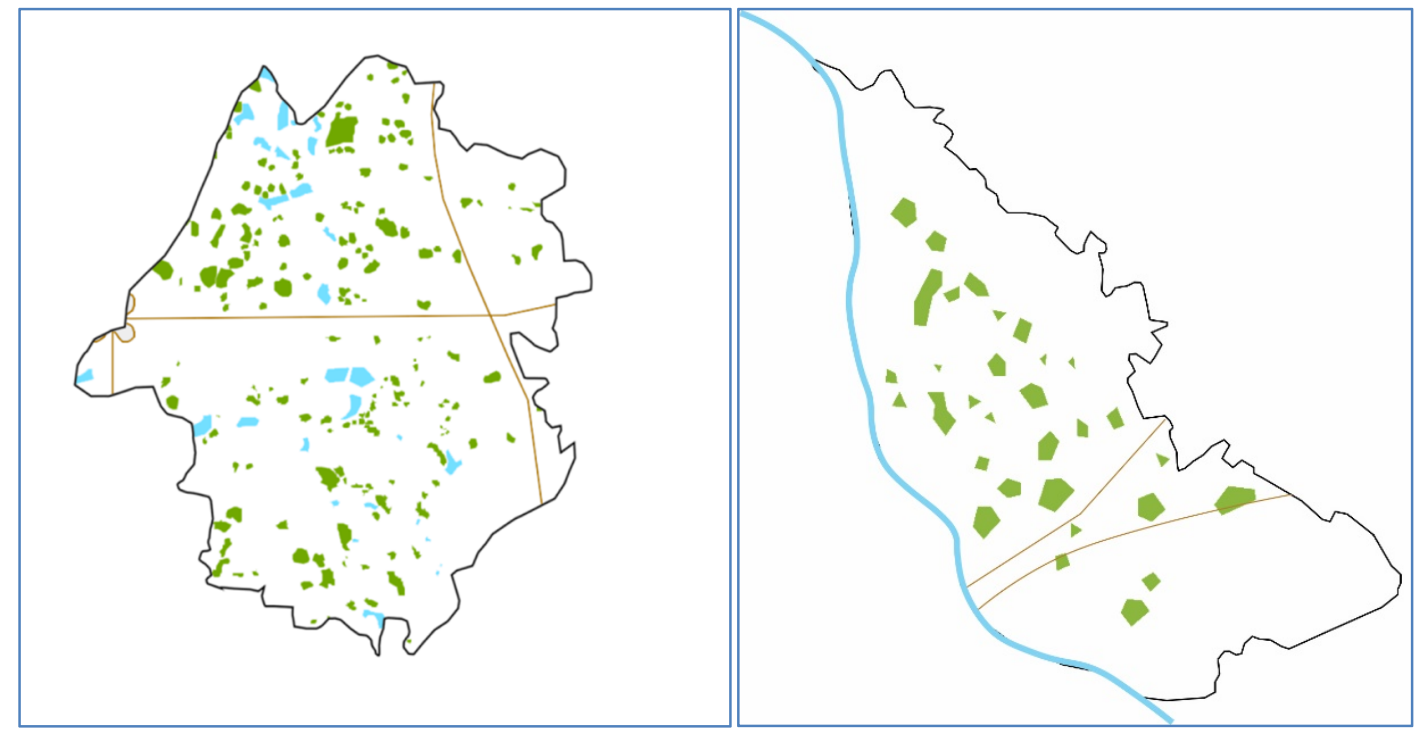

Figure 4. The spatial distribution of linpan agglomeration (green dots) with roads (brown line) and water system (blue) in case-study sites, Dantu Village (left), and Paotong Village (right), which were visualized with satellite images.

Table 1. Metrics of limpan landscape in two case-study sites.

\begin{tabular}{ccc}
\hline Metrics & Paotong Village & Dantu Village \\
\hline Land area $\left(\mathrm{km}^{2}\right)$ & 1.87 & 6.45 \\
Population density $\left(\right.$ person $\left./ \mathrm{km}^{2}\right)$ & 1224.60 & 497.98 \\
Mean area of linpan unit $\left(\mathrm{m}^{2}\right)$ & 8342 & 3000 \\
Average interval distance $(\mathrm{m})$ & 273.98 & 395.50 \\
Linpan density (unit $\left./ \mathrm{km}^{2}\right)$ & 17.9 & 26 \\
Carrying capacity of linpan unit (person/unit) & 68.41 & 19.15 \\
\hline
\end{tabular}

The density and size of linpan units are well corresponding to the topographic location, population density, availability of water supply, and the accessibility to highways or marketplaces $[16,62]$. For Paotong Village, where the flatlands have been irrigated by the Dujiangyan Irrigation System for over hundreds of years and the population density is as high as 1224.60 person $/ \mathrm{km}^{2}$, the linpan density is 17.9 unit $/ \mathrm{km}^{2}$ (see Table 1). On the contrary, for Dantu Village the population density is 497.98 people $/ \mathrm{km}^{2}$, but linpan density is $26 \mathrm{unit} / \mathrm{km}^{2}$, accounting to $45.25 \%$ higher than Paotong Village. This comparison illustrates a higher carrying capacity of the linpan unit in the plain area (68.41person/unit) than in the hilly area (19.15 person/unit). Previous studies also indicated that the density of linpan in the whole Chengdu Plain is about 10-15 units per square kilometer. There are only around 10,300 big linpan (with over 10 households), making up only $7.3 \%$ of the total amount of individual linpan units of the Chengdu Plain $[60,63,64]$. Thus, a small linpan with a few households $(<10)$, accounting to over $70 \%$ of the total linpan, is the dominant mode adopted traditionally by local 
rural societies. For our case-study sites, the mean area of the linpan unit is $8342 \mathrm{~m}^{2}$ in Paotong Village but $3000 \mathrm{~m}^{2}$ in Dantu Village, which indicates that the general size of the linpan is smaller in hilly area than in plain. Considering the sustainability of land use, the fact that more but smaller linpan units were found in Dantu Village actually unraveled a kind of traditional knowledge or practice which could lighten and disperse spatially the population pressures on the relatively infertile lands through landscape planning and management.

\section{Results}

Briefly speaking, an ecosystem can be defined as a complex made up of living organisms, physical environment, and their interrelationships in a particular unit of space [45]. This means an ecosystem can be of any size and may occur in a small (linpan unit) or big (linpan system), within which the biotic and abiotic components interact through nutrient cycles and energy flows. The term "ecosystem services" refers to the benefits gained from the complicated interactions between humans and the environment including various functions of an ecosystem $[65,66]$. Just as other ecosystems, the services provided by linpan regardless of individually or collectively could also be grouped into four primary categories [45], which will be elaborated in the following sections (see details of four categories of ecosystem services delivered by linpan system in Figure 5).

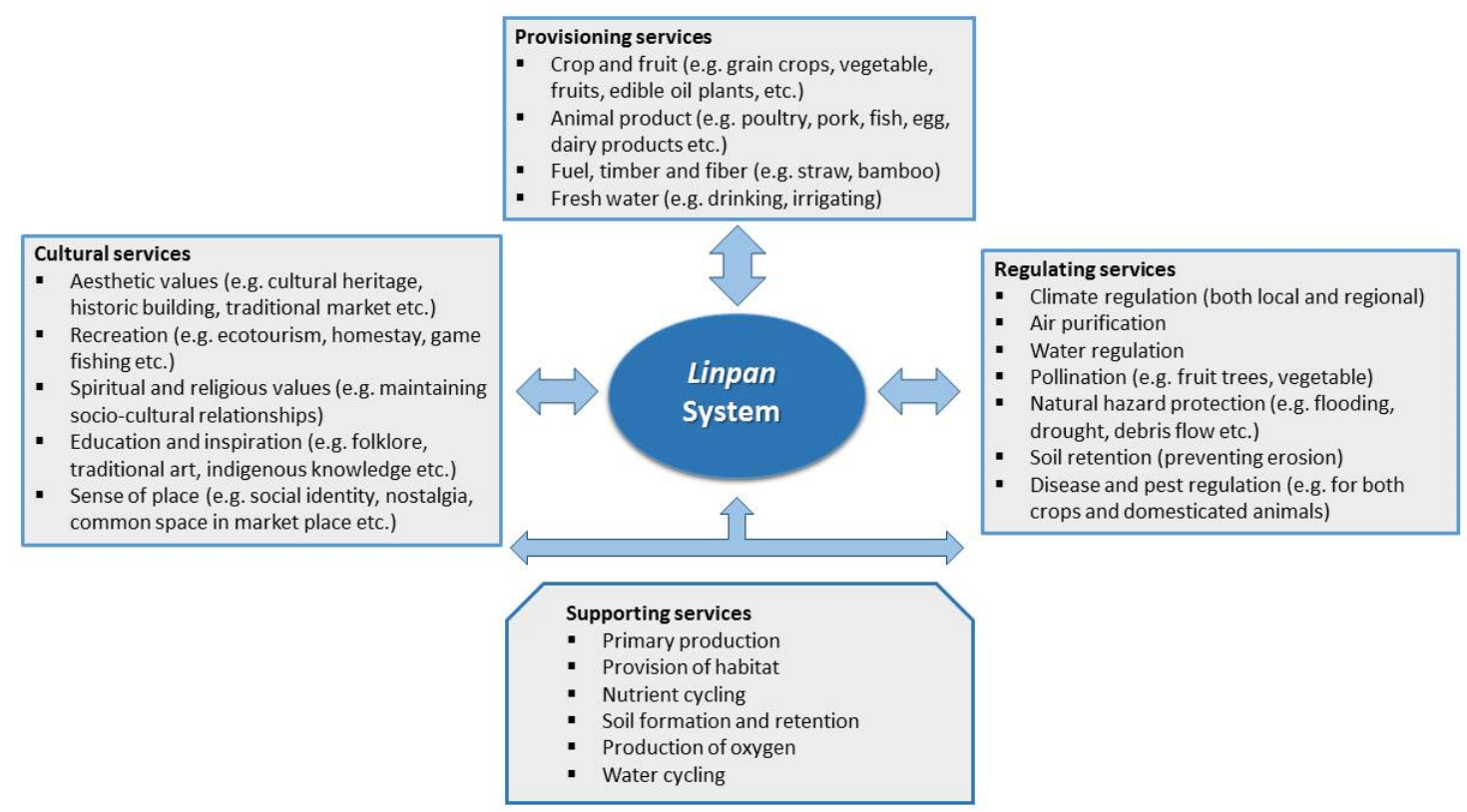

Figure 5. Four categories of linpan's ecosystem services, including detailed deliveries of provisioning (Section 3.1), regulating (Section 3.2), cultural (Section 3.3), and supporting (Section 3.4) services, with the definitions given by the Millennium Ecosystem Assessment [45].

\subsection{Provisioning Services}

Linpan, providing multiple goods and services to livelihood, are integrated rice-based farming systems (e.g., rice-duck culture) and lotus-based farming systems (e.g., lotus-fish culture, lotus-duck culture) with numerous cereal crops, vegetable, cash crops, and fish varieties/genotypes. The cultivation of grain crops mainly including rice, wheat, maize, potato, and sweet potato is the main agricultural production. It was found recently that even as early as around $2700 \mathrm{BC}$ a combined system of rice and foxtail millet agriculture appeared in sites of the Baodun culture on the Chengdu Plain [67], which indicates a very long history of rice cultivation in this region. In 2015 the farming fields for crop cultivation was 683,900 hectare in Chengdu, among which the area for grain crops was 365,700 hectare, making up 53.5\% [68]. However, during the period from 2002 to 2015 the cultivated fields for grain crop decreased by about $32 \%$ due to urbanization and alternation of livelihoods in rural areas [68]. 
Regarding the case-study sites, the agriculture is mixed with the cultivation of grain crops (e.g., rice, wheat, maize, potato, sweet potato), vegetable (e.g., eggplant, chili pepper, pumpkin, cucumber, radish, cabbage, cauliflower, etc.), and fresh fruits (e.g., mandarin, loquat, pear, peach, plum, shaddock, strawberry, cheer, etc.). According to the survey, respondents in the two villages ranked grain crop cultivation as the top provisioning service, i.e., accounting to $84 \%$ in Dantu Village and $82.5 \%$ in Paotong Village (Figure 6). In Paotong Village, where flat rice paddy is the mainland cover, the yield of rice even makes up $70-80 \%$ of the annual grain production. However, in Dantu Village, where soils are not so fertile, the annual yield of rice accounts to about $50-60 \%$ of grain yield, following with maize $(15 \%)$ and wheat (10\%). Sweet potato was introduced to Chengdu Plain about 200 years ago [49] and became one of the main crops especially in gently hilly areas, such as Dantu Village, where it is always cultivated by local farmers while seasonal droughts coming. Another trend could be also found in the whole Chengdu Plain where the fields for wheat cultivation declined from $20.56 \%$ of the total cultivated lands in 1990 to $5.05 \%$ in 2018, but the fields for maize cultivation increased from $6.58 \%$ to $13.21 \%$ [69]. According to the interviews and group discussions with local people, the preference of maize cultivation by local farmers is mainly due to the increasing market demand, on the one hand, mostly used for fodder processing and liquor production, and the better tolerance than wheat to weather extremes (e.g., drought and cold waves) and biological threats (e.g., disease, pest, and increasing bird-eating such as in Dantu Village).

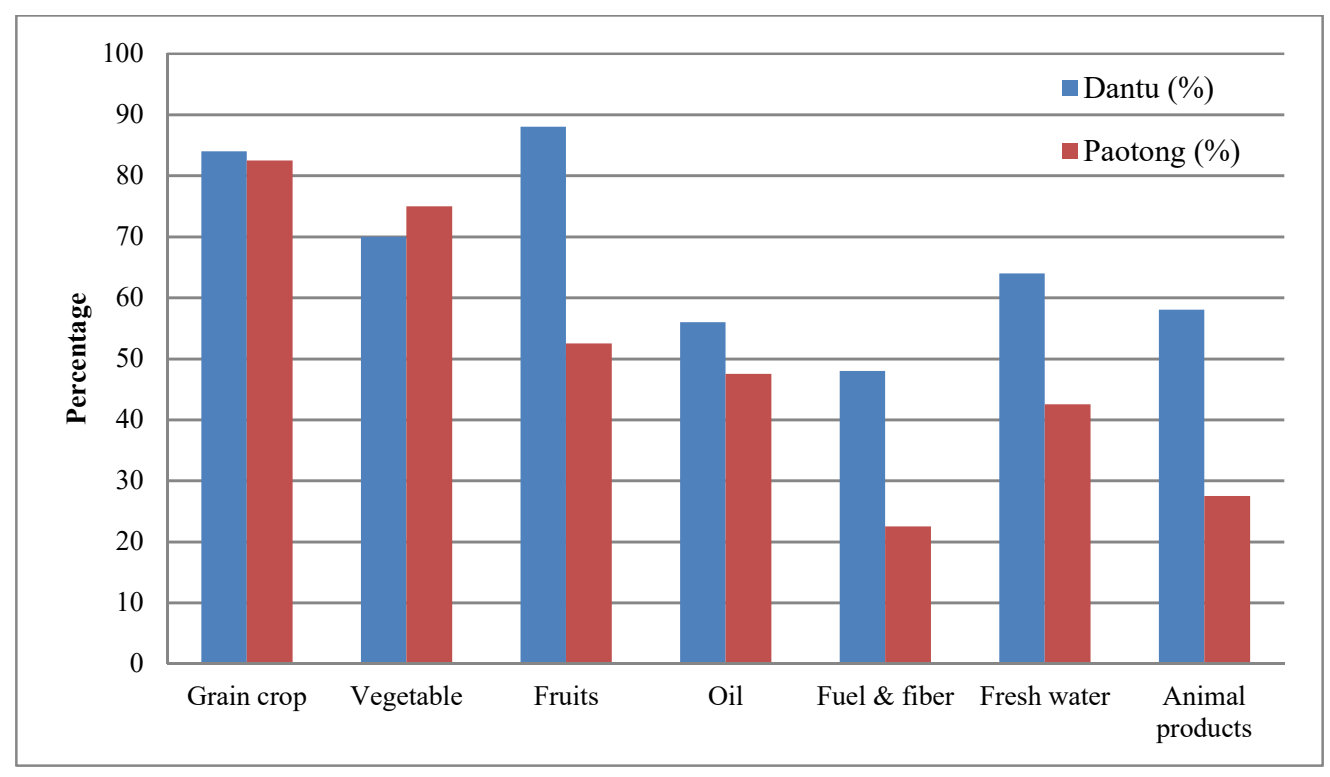

Figure 6. The importance of provisioning services perceived by respondents in Dantu Village and Paotong Village.

Agroforestry is a common model used by local farmers in managing their agricultural production. Fruits, mainly including fresh fruits such as peach, mandarin, loquat and apricot, and nuts such as walnut and gingko, are commonly cultivated by farmers around their houses or in their home gardens and plantations. In Dantu Village fruit production was the service perceived to the very important, being recognized by $88 \%$ of respondents, where fruit trees were planted in a large scale on sloping lands, but in Paotong Village the importance of fruit production was relatively low (recognized by $52.5 \%$ of respondents) (Figure 6). In recent years, due to the unstable fruit markets, the large-scale cultivation of fruits such as strawberry, mandarin, apricot, and loquat in Dantu Village has been altered frequently, which led to economic losses of local farmers.

Various seasonal vegetables, for self-consumption or sale, are traditionally cultivated under these fruit trees, which form a vertical structure of agroforestry. However, newly occurred cultivation of vegetables on a large scale for marketing purposes could be found in both Paotong Village and Dantu 
Village. Vegetable production was thought by over $70 \%$ of respondents in the two surveyed villages as one of the most important provisioning services. In terms of the whole Chengdu Plain, the percentage of cultivated areas for vegetables increased from $7.91 \%$ of the total cultivated lands in 1990 to $22.77 \%$ in 2018 [69]. Traditionally, rape is not only a kind of vegetable but also (its seed) used for the production of edible oil in the Chengdu Plain. The total area for rape cultivation in Chengdu Plain in 2018 was about 0.13 million hectares, accounting for $18.15 \%$ of the total cultivated lands [69]. In both Paotong Village and Dantu Village rape has become the largest planted crop during the wintertime.

Traditionally, after harvesting rice and wheat, crop straw became the important firewood or building material for thatched roofs or handmade crafts. Some straw was also burned in the fields for fertilizing purposes, which however is not allowed anymore now due to the following air pollution. Bamboo used to be a very important material for building construction and furniture making in traditional rural areas. A thatched cottage with a bamboo wall daubed with plaster and straw roof used to be a typical scene in rural Chengdu [15]. Since the demand for bamboo declined, many bamboo groves were replaced by fruit trees or ornament trees. In Paotong Village, for example, local farmers have replaced their bamboo groves with ornament flowers/trees in the last few years due to the demands on greening urban and estate development. In Dantu Village, the importance of straw and fuelwood provision was recognized by $48 \%$ of respondents, comparing to $22.5 \%$ in Paotong Village (Figure 6). Forest and plantation enrichment on sloping lands in Dantu Village provide timber and fuel woods from thinning and pruning that local farmers can use for domestic construction or energy purposes. Although electronic appliances have been popularized in these rural areas, the dependency on fire-woods decreased, but local farmers still like to collect some fuels from their gardens or plantations nearby for reducing the cost of electricity use and recycling residues.

In Chengdu Plain diverse agroforestry such as the mulberry trees-silkworm-rice, fruit trees-honeybee keeping-vegetable, also provide other goods such as fiber, honey, ornaments, etc., with which people make efficient use of land and labor. In Dantu Village, interviewees admitted that fruit plantation intercropping with vegetable are very important for income generation, although they require higher management. Many genetic resources coming from these systems, such as spice and ornament plants, have supported local demands for hundreds of years and shaped the local cultural identities such as the famous Sichuan cuisine and various traditional handicrafts. A lot of medicinal herbs are collected from community forests or cultivated in the home gardens, which are very important traditional knowledge and practices for the health care of local people. In the marketplace of Dantu Village, for instance, there are normally over 50 species of medical herbs on sale during the marketing day.

In the linpan system, animal products mainly from pig, poultry, and fish, were perceived as the most important source for the nutrient provision and income generation of local people. Pig and poultry were raised at homesteads mainly for self-consuming, marketing, and manure provision. Due to the increasing demands on animal products, large-scale pig breeding farms or henneries occurred and competed with local smallholders. Fish farms were developed very quickly in Dantu Village with the engagement of private enterprises. This is the reason why over $50 \%$ of respondents in Dantu Village recognized animal production as an important service (Figure 6), which is much higher than that in Paotong Village (27.5\%). The fish ponds on low-lying lands can store rainwater during the raining season and irrigate farm fields nearby while drought coming, which enhanced the adaptive capacity of local communities against drought or heat waves.

\subsection{Regulating Services}

As a specific ecosystem complex in Chengdu Plain, linpan contributes to the regional regulation of climate, air, water as well as biogeochemical cycles. The linpan system as a whole influences the climate both locally and regionally and mitigates weather extremes such as floods and drought. At the regional scale, linpan plays an important role in climate regulation by either sequestering carbon (by crops, trees/bamboos) or emitting greenhouse gases (e.g., methane emission from rice paddy) [70]. It can also 
contribute to the purification of air through the woodlands surrounding settlements [43]. Land use and land cover change, such as the loss of linpan, can thus affect both temperature and precipitation in Chengdu Plain, impacting further the urban climate (e.g., aggravating the effect of 'Urban Heat Island'). In general, functioning ecosystems provide flexibility in rural landscapes to build adaptive capacity and cope with weather extremes such as increased risks of heatwaves, drought, and flooding [42].

At the local scale, when respondents were asked to identify the relative importance of particular regulating services, around $80 \%$ identified climate regulation as the most important services (Figure 7). Although only a few respondents seemed to perceive the role of ecosystems functioning for air purification (42\% in Dantu Village and $47.5 \%$ in Paotong Village), this service actually is also related to climate regulation. The pattern of houses in a linpan always reflects the environmental design of buildings in considering climate variability and seasonality in the subtropical region, i.e., hot summer, cold winter, and humid air. The shapes of a farmers' courtyard mostly present "L" shape, quadrangle shape (four-section compound form), or only embraced on three sides by buildings (three-section compound form) $[15,27,59]$. The main house of a courtyard regardless of its shape mostly faces sunny direction (south-facing, or southeast-facing) for absorbing enough heat in winter and keeping the adequately ventilated condition in summer. Water canals or ditches flowing through or around linpan may not only provide water for daily life but also transport fresh air for cooling down the temperature in summer.

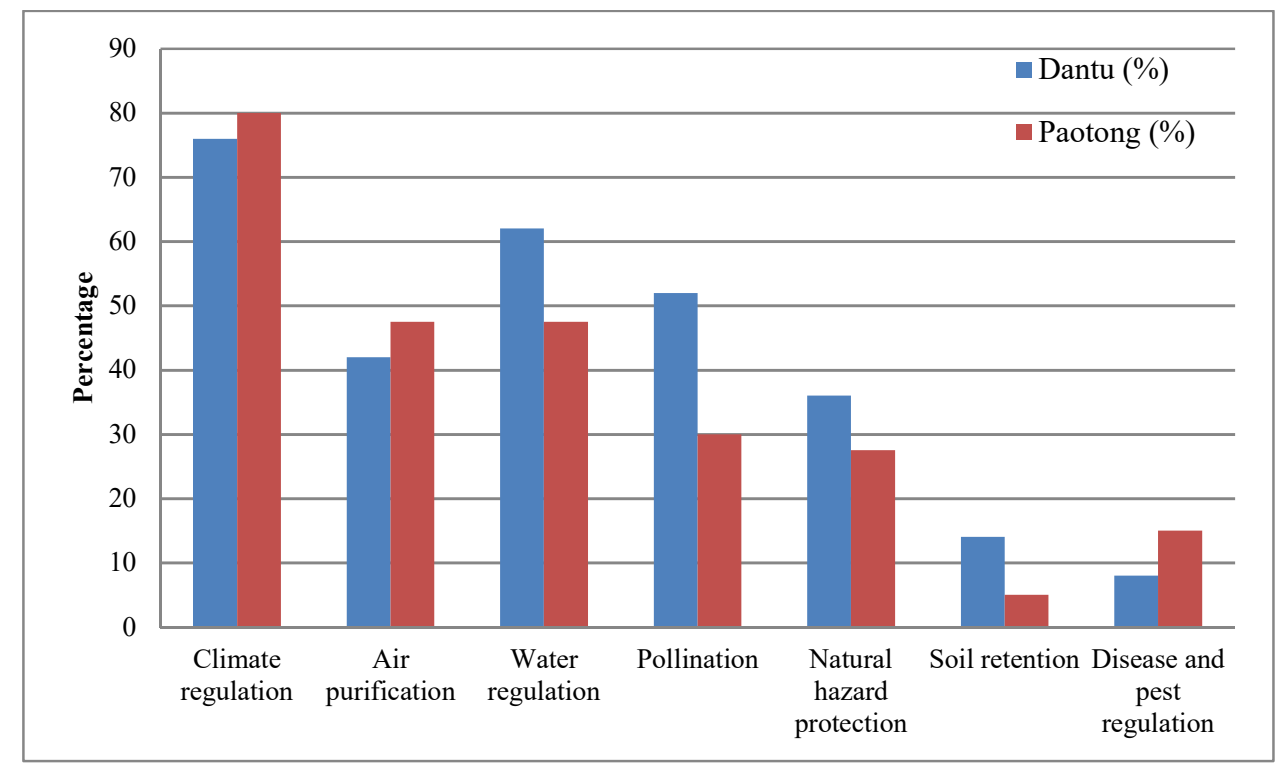

Figure 7. The importance of regulating services perceived by respondents in Dantu Village and Paotong Village.

During the interviews, the participants reported that trees and bamboo groves around their houses can function as a shelter for weather extremes, buffering the strike of high wind, heatwave and cold wave which were recognized by as high as $76 \%$ of respondents in Dantu Village and $80 \%$ in Paotong Village, and avoiding the threat of natural hazards including mainly flood and drought (by $36 \%$ and $27.5 \%$ respectively in Dantu Village and Paotong Village). In previous studies, it was identified that linpan may affect the temperature with cooling air in summer and reducing wind speed in winter [56]. The temperature difference between the outside and inside of a linpan would become smaller along with the increasing base area, which means a suitable size of linpan is important for the comfortable micro-climate [56]. For those farming fields around linpan, the micro-climate also becomes mild and humid throughout the year due to the regulation of tree/bamboo groves [15], which could be further beneficial to crop growth. 
Linpan is integrated well with water system (river and canal system) and wetland (ponds and rice paddy) and thus works as an important component of the whole Dujiangyan Irrigation System (watershed) for the regulation and purification of water resource locally and regionally [15]. The timing and magnitude of runoff, flooding, and aquifer recharge can be strongly influenced by changes in the linpan system (network), including, in particular, alterations of water storage potential of the system. In Dantu Village, where the topography is gently hilly, the recognition of local people on the importance of water regulation was higher (62\% of respondents) than in Paotong Village $(47.5 \%)$. Within or around a linpan unit there are a number of ponds that could be used to collect rainwater and runoff water for irrigating fields or supply daily life especially during dry seasons [27]. In Dantu Village, for instance, many water ponds (including fish ponds) nearby linpan were developed in the last few decades due to the worse irrigating condition in comparison to Paotong Village. Vegetative cover of linpan, such as bamboo groves, also plays an important role in soil retention and preventing surface erosion or even debris flow in hilly areas [15,43]. In Chengdu Plain linpan network can be a source of impurities in freshwater but also can help to filter out and decompose organic wastes introduced into water bodies of the Dujiangyan Irrigation System.

Pollination is one of the most important regulating services provided by the linpan system. In Dantu Village, for example, local farmers like to keep a small apiary for honey production in their home gardens as well as fruit plantations. In both of the surveyed villages, the importance of pollination was recognized by $52 \%$ of respondents in Dantu Village and 30\% in Paotong Village. The higher recognition in Dantu Village was perhaps due to many households engaging in fresh fruit production. Beekeeping also provides an important source of income for many rural households. There were 23 flower-visiting pollinator species found in the Chengdu Plain, including 4 species of managed bees and 19 species of wild pollinators [44]. This kind of diverse community of pollinators generally provides more effective and stable crop pollination than any single species [71], especially for the cash crops or fruits in the linpan system. However, the increase of introduced bees has led to the decline of native species. Due to the loss of available habitats and the disappearance of home gardens in the Chengdu Plain, it was reported that the managed bees within the home gardens decreased by $62.05 \%$ and wild pollinators decline significantly [44]. With a global perspective, threats include land-use change, intensive agricultural management and pesticide use, environmental pollution, invasive alien species, pathogens, and climate change [71]. However, explicitly linking pollinator declines to individual drivers is limited by data availability or complexity in the Chengdu Plain, although a few interviewees in case study sites informed that these drivers often affect pollinators negatively.

\subsection{Cultural Services}

The linpan system supports the interaction between humans and nature and is a vital source of inspiration for culture and art. In addition, it is also a living space for inter-household interactions, a tomb yard for family and clans, and a symbol of family/community prosperity. In history, the linpan landscape provides a rich source of inspiration for art, folklore, architecture, and advertising in Chengdu, which formed the famous "Shu Culture" (Shu: an old name of Sichuan) in southwest China. The ancient "Shu Culture" due to a number of large-scale immigration and merging with various alien cultures (e.g., Ke Jia Culture) has been refreshed and reformed progressively [60]. Some linpan' residents living to the east of Chengdu nowadays still speak Ke Jia dialect (a kind of Cantonese), who are immigrants in the early Qing Dynasty (about 300 years ago) from southeast China. As an ancient trading nexus, where ancient southern Silk Route trudging from China to South Asia and Tea-Horse Trading Road from the east (farming territories) to the west (pastoral territories), Chengdu embraces diverse cultures, and finally develops a specific local knowledge and cultural system $[57,60]$.

Generally, the linpan landscape lacks the nucleated villages and instead features farmhouses scattered among the fields singly or in small clusters [60]. In order to maintain a rational carrying capacity of the environment, the scale of a limpan unit and the distance between linpan units are controlled traditionally through breaking up the big family and living apart after a son married [16]. 
This is one of the reasons why the linpan system presents a decentralized model at the landscape scale, which is different from the models in northern China or even the downstream of the Yangtze River where a village usually presents much more centralized $[17,19]$. A small linpan generally has only a few peasant households, however, a large linpan may contain dozens of households [15,48]. In history, such social organizations may take the form of customary laws and practices as well as ceremonial, religious, and/or spiritual experiences. A man usually was not only born in a linpan but also entombed under a bamboo grove of the same linpan. Thus, the stability and capacity of linpan system to provide goods and services critically depend upon rural communities having and sustaining diverse and complex forms of social organization (kinship, territoriality, settlement, etc.), culture (languages, values, rights, etc.), modes of production, and labor allocation.

Traditionally, those farmers living in linpan link their agricultural activities and daily life with towns or urban through rural markets, which are the periodic and distributed on linpan landscape with a certain serving range [72]. In Dantu Village, for instance, a periodic market with a history of over two hundred years opening for local people once per two days provides a traditional marketplace for them to sell agricultural products and homemade crafts and purchase what they need for daily life and agricultural production. Residents in linpan going to the markets nearby twice or three times per ten days not only for an economic purpose but also social (e.g., communicating information, meeting friends or seeing doctor) and cultural (e.g., visiting temples for religious activities, watching a cultural performance or celebrating festivals) [73]. Even nowadays, although the conditions of transportation and communication have been changed, farmers still rely on these marketplaces, for requiring administrative and social services, achieving spiritual and recreational purposes, or sending their children for education. The rural market is thus a common space shared socially by local communities, and marketing activity, i.e., going to market periodically, becomes one of the most important social intercourses for local people [60], which further makes the "sense of place" for local people and was highly recognized by local people in Dantu Village ( $54 \%$ of respondents) (see Figure 8 ).

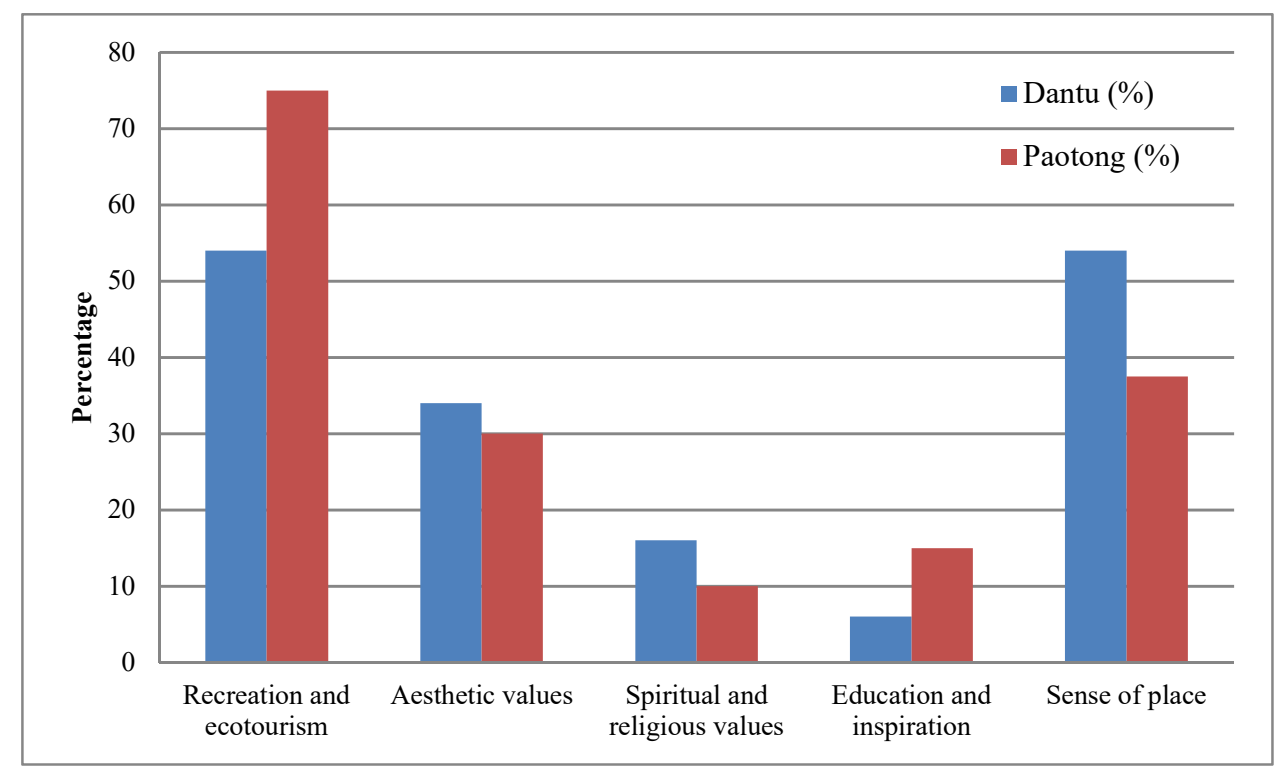

Figure 8. The importance of cultural services perceived by respondents in Dantu Village and Paotong Village.

As an integrated ecosystem complex, the linpan system also provides amenity services to rural and urban people and particularly attracts urban tourists. Colorful patches from rape flowers and ripening orange, peach, and loquat fruits bring opportunities for the development of rural tourism, which further led to the increased recognition of the importance of recreation and aesthetic values (by over $30 \%$ of respondents). In both of case-study sites, linpan based eco-tourism, including Farmers' 
Homestay ("Nong Jia Le" in Chinese), fishing game, or rural hiking, has been developed recently, with which urban people often spend their leisure time-based in part on the aesthetic value of rural landscapes. This kind of rural ecotourism was thought to "contribute to maintaining the indigenous character of rapidly urbanizing rural landscapes with the use of appropriate inheritance and renovation ways" [74]. This is the reason why among cultural services, ecotourism was the service perceived to be the most important in the two villages, recognized by $75 \%$ of respondents in Paotong Village and $54 \%$ in Dantu Village respectively (Figure 8). The high recognition of tourism in Paotong Village was perhaps encouraged by neighboring villages (e.g., Qinggangshu Village) where tourism has become an important income source after reforming land property rights [75]. For Dantu Village the historic street for the periodic market has been preserved as a heritage site by the local government recently which is arousing the emotions of the local community to develop rural tourism.

\subsection{Supporting Services}

Supporting services of linpan system are those that are necessary for the production of all other ecosystem services in this landscape. More precisely the transformation of energy, the cycling of water and nutrients, the soil formation, and retention are the major services of this group, which support not only linpan systems in rural Chengdu but also the urban center. Primary production (e.g., food, fodder, fuel, fiber, etc.) and production of atmospheric oxygen (through photosynthesis of plants) by forests, wetlands, and farmlands in the linpan landscape support all of the organisms including human being ourselves in this region.

Linpan system, integrating various ecosystems and creating diverse ecological interfaces, provides ideal habitats for local flora and fauna, thus containing much richer biodiversity than normal agricultural ecosystems. It was reported that 181 species of plants belonging to 146 genera and 76 families were found in the linpan system which forms a number of vegetation types [43,76]. Bamboo groves are typical shelter around linpan's settlements, which make up 32\% of the whole linpan's woodlots [26]. Evergreen broadleaved trees are typical in subtropical Chengdu which composed about $25 \%$ of linpan's woodlots with over 100 plant species [26]. The woodlands around the settlements provide the most important habitats within the linpan system for wildlife distribution. For example, various forest/bamboo groves are important places for birds' living which are further beneficial to controlling insects in the paddies nearby.

In Chengdu Plain home gardens or fruit plantations are popular within the linpan landscape and present an agroforestry style with a vertically spatial structure and enriching biodiversity. The capillary waterways including numerous canals and small ditches radiating in all directions provide corridors for wild species, on the one hand, many linpan or tree/bamboo patches, as small 'green islands' scattering in farming fields, play the role of 'stepping stone' for species dispersion or migration on the other $[14,59]$. In Dantu Village, combining with crop cultivation, the booming fish-farming has not only contributed to income generation but also supported the provision of various ecosystem services. Annually, farmers discharge water from ponds in February or March and then replenish in April or May from the hydraulic system. Mud (sludge) at the bottom of ponds are dug out and distributed on the farming fields as organic fertilizer due to the rich composition of fish excrements. Traditionally, pig rearing is one of the most important household productions in rural Chengdu, which provided nutrients (e.g., animal protein) as well as manure/fertilizer to farming fields. The water flowing through linpan with plentiful nutrients from forest litter, village sewage, and manure fertilizes farming fields during the watering periods in a year. This kind of traditional practice not only saves energy and labor in managing fields but also recycles organic "wastes" in the linpan system. 


\section{Discussion}

\subsection{Considering Dynamics of Services Delivery in Cultural Landscape Management}

The linpan system represents a localized landscape that has been developed over time through the interaction between humans and the environment and appears to have stabilized or been resilient in the last hundreds of years with the functioning of the Dujiangyan Irrigation System in Chengdu plain $[10,19]$. This system with its diverse form and configuration provides plentiful services to human wellbeing and has a strong connection with the local environment, biodiversity, and socio-cultural background. However, the delivery of ecosystem services by the linpan system is a dynamic process, which is changeable with the socio-economic development and human demands on various benefits or values. Like most parts of China, the Chengdu plain has experienced a great change in the last few decades. Many linpan units scattering traditionally on the plain are being replaced by centralized settlements, urbanizing townships, and industrializing zones progressively driven by development strategies and programs $[4,10,17]$. These interventions have reshaped and restructured rural landscapes, and then influenced the capacity of rural ecosystems in providing their services. For example, the urbanization in Chengdu with the rate increasing rapidly from $28.38 \%$ in 1978 to $53.72 \%$ in 2000 and then $73.12 \%$ in 2018, and meanwhile the cultivated lands lost about $25.87 \%$ in the last 40 years [69]. The expansion of built areas unavoidably led to the shrinkage of the agricultural landscape and the decrease of services provision from the linpan system.

Nowadays, market penetration, rural-urban migration, population growth, governance reform, implementation of new agro-technology, and other drivers have accelerated the pace of changes in the agricultural system and its services $[4,10,21,22]$. For example, the traditional provisioning service of grain crop production was diversified to vegetable, cash crops, fruits, and animal production in order to meet the increasing demands of the urban population on nutrients. In Paotong Village, which is located nearby an urban center and has an ideal irrigation condition, many farming fields were used by local farmers for commercial vegetable or ornament plant production. In contrast, in Dantu Village where the urbanizing process is relatively slow and most of the farming lands are located on gentle slopes, fresh fruit production was recognized by local people as the top provisioning service with $88 \%$ recognition of respondents. The different geographical locations and environmental conditions may influence the marketing opportunity which further results in the different prioritization of provisioning services by smallholder farmers. The preferences for specific products, however, are always impacted by the frequent fluctuation of markets. In Paotong Village, for example, local farmers replaced their bamboo groves with ornament flowers/trees plantation a few years ago, but later they had to give up ornament plants instead of green chives cultivation due to the changing market. In Dantu Village the alteration of fruit cultivation was also frequent in the last few years in order to respond (sometimes passively) to the change of market demands. A changing world thus needs a dynamic rather than static viewpoint while assessing ecosystem services of linpan system and integrating them into the adaptive management strategies.

\subsection{Linking Material and Non-Material Values in Agricultural Heritage Preservation}

Historically, provisioning services are the most important services recognized commonly by people to which humans paid the most attention due to the direct economic benefits. Previous studies have found that human preferences toward ecosystem services focus first on provisioning services, followed by regulating services, and finally, on cultural services [38]. For most landscape management strategies people favored the delivery of provisioning services at the expense of regulating and cultural services [77]. Since their values are more tangible and identifiable by society [78], provisioning services are always given a strong emphasis on development or preservation planning. In the agrarian society of the Chengdu plain, farmers' preferences toward provisioning services are naturally due to the cognitive connection of their well-being with the life-supporting environment and traditional culture. However, our results also show that the recognition of regulating services and cultural services 
is rising, especially for young people who are better educated or work in urban areas as laborers occasionally or seasonally. For example, with the booming market of rural tourism, local people are aware that the potential tangible (economic) values could come from intangible (e.g., aesthetic) ones. The saliency in the recognition of ecotourism development in case-study sites reflects the rising awareness of local communities on different categories of ecosystem services, which could be explained by a combination of factors, including development motivation, communication media or advertising, knowledge dissemination, and propaganda about environment conservation in particular among youth. According to the interviews and group discussions in case-study sites, local people recognized a highly diversified flow of services that could be attributed to their own well-being which is closely connected with various ecosystem services rather than material values alone.

Linpan, as a cultural landscape, characterizes a few remarkable features, such as maintenance of significant agricultural biodiversity and resilient production system, and is enriched with valuable cultural services $[10,55]$. Cultural services, somewhat vaguely defined as non-material benefits people obtain from ecosystems through spiritual enrichment, cognitive development, reflection, recreation, and aesthetic experiences [45], create strong ties between humans and their natural surroundings and even play a crucial role in "sense of place" of a landscape. Compared to many natural ecosystems, cultural landscapes stamped by agriculture and/or forestry have much greater potential to expand the supply of ecosystem services including both material and non-material values [37]. A cultural landscape, as an archive of the traces of the history of man and nature, can be thus considered a holistic indicator of sustainable development [78]. However, although there is broad agreement on the importance of incorporating cultural services into policy strategies and decision-making, there is a lack of a standardized approach to quantify these services for satisfying demands. Cultural services are rarely taken into consideration in current research activities and even lack of ecosystem services assessments [77]. It should be appreciated for the preservation of the linpan system in Pidu District as the National Important Agricultural Heritage Systems (NIAHS), which indicates a common recognition of the importance of cultural services. In Paotong Village, for instance, the traditional features of the linpan system were required to be maintained while implementing new development programs. This preservation effort may trigger a great opportunity for deeply understanding how local communities or civic societies maintain the structure and function of a human-dominated landscape and sustain its material and non-material values in the long run.

\subsection{Integrating Linpan's Services for Holistic and Inclusive Development}

Nowadays the ecosystem services approach has become prominent in conservation science and practice [37] and been already integrated into landscape planning, management, and decision making $[37,78]$. By linking ecosystem functions with human livelihood quality, the concept of ecosystem services aims to justify nature conservation and environmentally sensitive management [79], which provides an innovative and powerful tool in terms of quantifying, accounting, and valuating different services provided by a specific landscape unit. However, compared to a large number of studies on natural ecosystems, the number of studies investigating ecosystem services in urban-rural areas is less than $10 \%$ of all ecosystem services publications [42]. Rural landscape, such as the linpan landscape in Chengdu Plain, is an undividable part of the urban-rural continuum which continues to be the provider of various goods and services to rural as well as urban residents. Cities always depend on the productive and assimilative capacities of the rural ecosystems well beyond their boundaries [80,81]. This means ecosystem complex in rural areas around an urban such as Chengdu also contributes to the functioning, resilience, and sustainability of a city as a whole. In 2018, the metropolitan government of Chengdu proposed a new program called "Constructing Park City" with the main aim of increasing green space and ecological infrastructure in both urban and rural areas. Meanwhile, a national strategy "Rural Revitalization" aiming at production development, environment protection, culture preservation, and livelihood improvement was initiated in China. All of these newly launched programs require a holistic consideration of both urban and rural ecosystems while making landscape planning. 
Although the ecosystem services provided by the linpan system were described as four categories, these services are interactive and supportive of each other through a complicated pathway. In order to generate the preferable services and obtain the required benefits, local people usually manage the linpan system in an adaptive approach and synergize the benefits or values to sustain services provision (Figure 9). Regarding the linpan system, local ecological knowledge has played a crucial role in developing management practices that secure essential ecosystem service supplies for maintaining the livelihood of local people [55]. In order to well adapt to environmental and non-environmental changes, farmers, based on their knowledge and experience, usually recombine the benefits and values of the socio-ecological system and recognize both the direct 'use-values' of ecosystems (e.g., provisioning services and regulating services) as well as the very significant 'non-use values' (e.g., cultural services and supporting services) associated with landscape management. This kind of flexibility corresponds to the adaptive capacity of local communities to environmental or socio-economic changes and the high level of socio-ecological resilience against external pressures or shocks. Of course, guiding systemic processes to obtain beneficial outcomes involves continual decision-making adjustments in response to multiple factors and their interactions [37,82]. Different stakeholders also hold different values and perceptions toward ecosystem services [38]. Therefore, more efforts should be put in the future to implement effectively equal and inclusive growth strategies and policies with the involvement of all stakeholders, especially local communities for coordinating and sharing the ecosystem services of the linpan landscape.

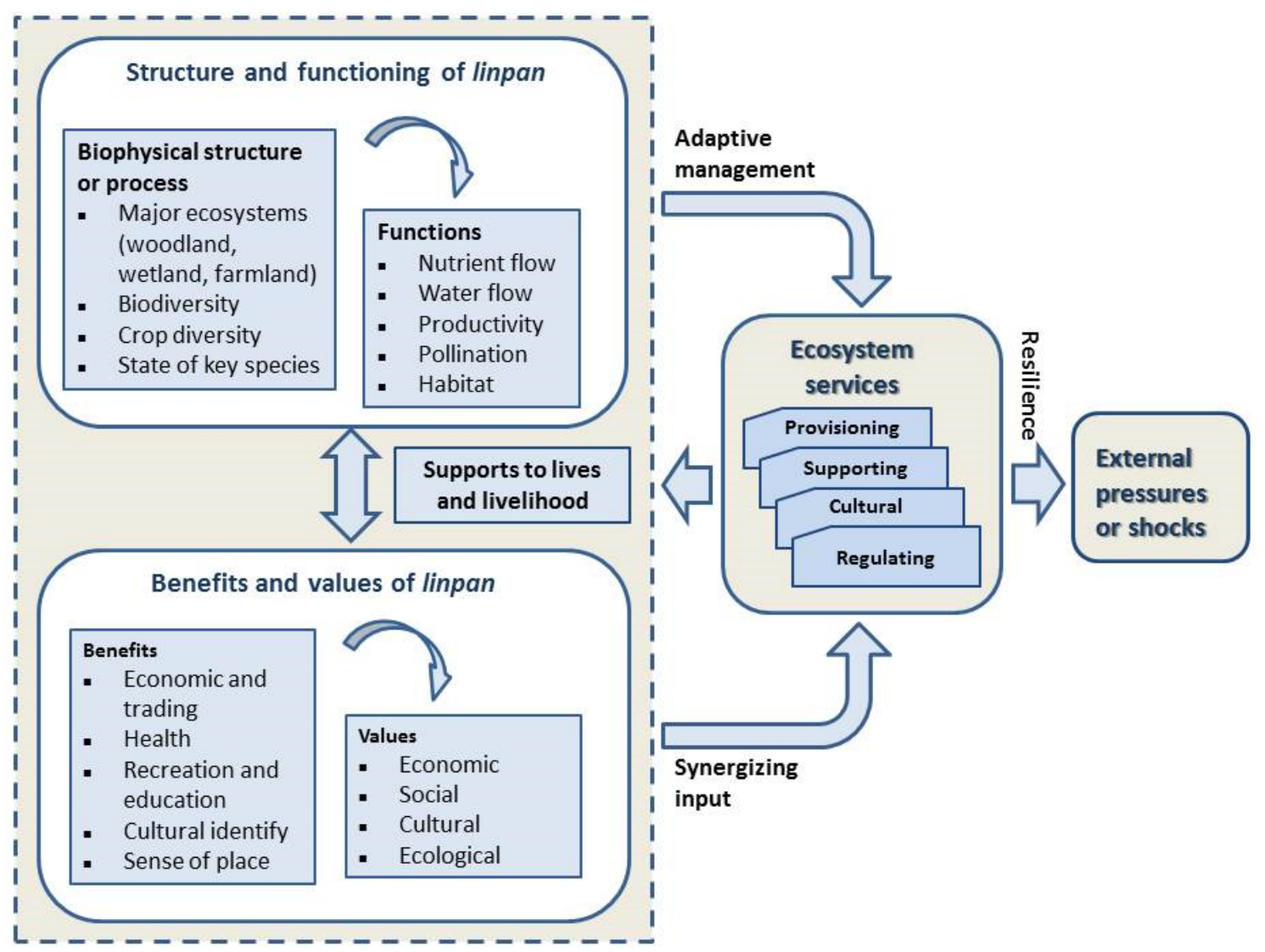

Figure 9. Integrative management of ecosystem services for enhancing the socio-ecological resilience of the linpan system.

\section{Conclusions}

As a cultural landscape, the linpan system in Chengdu Plain has continued to provide various ecosystem services to rural as well as urban people or even the whole regional socio-economic system. 
With the rapid development in the last few decades in China, this landscape has been changed by various drivers and eroded by ambitious development plans. However, sustainable urbanization cannot be achieved by only focusing on infrastructure development and investment, it also requires green public spaces and ecosystem services provided by a rural landscape. Like other cities in China, rapid urbanization in Chengdu requires integrating the initiation of rural ecosystem research into landscape planning and management, promote the sustainable delivery of ecosystem services from rural landscapes, and create the opportunity for green development of the whole city.

This study shows that the linpan system is a kind of specific ecosystem complex in Chengdu Plain integrated with forests, wetlands, farming fields, and humans' dwellings. It is very important for local people due to not only the provision of food security and material products, but also climate regulation, air, and water purification, and cultural values. Various services including material and non-material values delivered by the linpan system were highly recognized by local people, but the perceived importance of services was changeable with the socio-economic development, market fluctuation, and people's awareness rise.

While integrating ecosystem services of the linpan system into landscape management and preservation, approaches and policies should be flexible enough for better adapting to the change of environmental and socio-economic conditions. Cultural services should not be neglected within the preservation framework of important agricultural heritage systems in the future. For synergizing multiple services of the linpan system into holistic and inclusive strategies regarding city development, the results of this study are hopeful to be applied in the following planning and management practices and contribute to explore new approaches for quantitatively and qualitatively assessing both tangible and intangible values of the rural landscape. Finally, this study indeed hopes to recall the common recognition and awareness on the importance of ecosystem services delivered by the linpan landscape, which undoubtedly could contribute to the current development program 'Constructing Park City' in Chengdu with a holistic consideration of the urban-rural continuum.

Author Contributions: Conceptualization, N.W., S.W.; literature review, S.W., N.W.; investigation, S.W., B.Z.; writing-Original draft preparation, S.W.; writing-Review and editing, N.W., S.W., B.Z.; supervision, N.W. All authors have read and agreed to the published version of the manuscript.

Funding: The first author would like to highly acknowledge and appreciate the funding from the Quaternary Research Center and the China Studies Fellowship at the University of Washington for supporting the academic research and field survey. This research was funded partly by the Science and Technology Department of Sichuan Provincial Government, China (Grant No. 20ZDYF1645).

Acknowledgments: The authors would like to thank all colleagues and students from the University of Washington and Sichuan University who supported the fieldwork in Pixian County (or called 'Pidu District' after 2016) during the field survey, and shared their valuable literature later. It would be very appreciated for Hong Fei supporting the basic map preparation and Shaoliang Yi, International Centre for Integrated Mountain Development (ICIMOD) for his valuable suggestions during the draft preparation. Thanks should be especially given to Daniel Abramson, Department of Urban Design and Planning, University of Washington for his provision of valuable literature.

Conflicts of Interest: The authors declare no conflict of interest.

\section{References}

1. Cai, J.M. Urbanization in China-Functional Orientation, Mode Selection and Development Trend; East Publishing Centre: Shanghai, China, 2019; pp. 1-159.

2. Fan, G.; Guo, W.D. Rethinking China's urbanization and Metropolis; China Economic Publishing House: Beijing, China, 2017; pp. 1-266.

3. Ye, Y.; LeGates, R. Coordinating Urban and Rural Development in China: Learning from Chengdu; Edward Elgar Publishing: Northampton, MA, USA, 2013; pp. 1-424.

4. Peng, W.F.; Wang, G.J.; Zhou, J.M.; Zhao, J.F.; Yang, C.J. Studies on the temporal and spatial variations of urban expansion in Chengdu, western China, from 1978 to 2010. Sustain. Cities Soc. 2015, 17, 141-150. [CrossRef]

5. Zhang, L.; LeGates, R.; Zhao, M. Understanding China's Urbanization: The Great Demographic, Spatial, Economic, and Social Transformation; Edward Elgar Publishing: Northampton, MA, USA, 2016; pp. 1-424. 
6. Chen, J.C.; Zinda, J.A.; Yeh, E.T. Recasting the rural: State, society and environment in contemporary China. Geoforum 2017, 78 (Suppl. C), 83-88. [CrossRef]

7. Hayward, J. Beyond the ownership question: Who will till the land? The new debate on China's agricultural production. Crit. Asian Stud. 2017, 49, 523-545. [CrossRef]

8. Xiao, L.S.; He, Z.C.; Wang, Y.; Guo, Q.H. Understanding urban-rural linkages from an ecological perspective. Int. J. Sustain. Dev. World Ecol. 2016, 24, 37-43. [CrossRef]

9. Alberti, M. Advances in Urban Ecology: Integrating Humans and Ecological Processes in Urban Ecosystems; No. 574.5268 A4; Springer: New York, NY, USA, 2008; pp. 1-366.

10. Whiting, S.H.; Abramson, D.; Yuan, S.; Harrell, S. A long view of resilience in the Chengdu Plain, China. J. Asian Stud. 2019, 78, 257-284. [CrossRef]

11. Kroll, F.; Müller, F.; Haase, D.; Fohrer, N. Rural-urban gradient analysis of ecosystem services supply and demand dynamics. Land Use Policy 2012, 29, 521-535. [CrossRef]

12. Wolf, K.L. The changing importance of ecosystem services across the landscape gradient. In Urban-Rural interFaces-Linking People and Nature; Laband, D.N., Lockaby, B.G., Zipperer, W.C., Eds.; American Society of Agronomy: Madison, WI, USA, 2012; pp. 127-146.

13. Urban and Rural Construction Bureau of Chengdu. Chengdu planning: Protect linpan landscape in western Sichuan. Urban Plan. News Rep. 2007, 17, 8-9. (In Chinese)

14. Yang, Q.J.; Li, B.; Li, K. The rural landscape research in Chengdu's urban-rural integration development. Procedia Eng. 2011, 21, 780-788.

15. Zheng, J. On ecological significance of forest domain in west of Sichuan. Shanxi Archit. 2010, 36, 50-52. (In Chinese)

16. Chen, Y.L.; Zhou, B.; Gong, H.; Cheng, Y.; Zhou, L. Harmony with environment—Study on the ecological significance of limpan in west Sichuan with a spatial perspective. Sichuan Archit. Sci. 2011, 37, 235-237. (In Chinese)

17. Shu, B.; Gao, T.N.; Zhao, Y.X. Research on intensive utilization of land and settlements protection under rural housing reconstruction in Chengdu Plain. Wit Trans. Ecol. Environ. 2013, 173, 231-238.

18. Li, K.; Yang, Q.J. Research of property rights institution in Chengdu's urban-rural integration development: A case study. Procedia Eng. 2011, 21, 700-706.

19. Abramson, D.B. Ancient and current resilience in the Chengdu Plain: Agropolitan development re-'revisited'. Urban Stud. Spec. Issue Artic. Environ. Gov. Urban Resil. Asia-Pac. 2019, 57, 1372-1397. [CrossRef]

20. Abramson, D.B.; Yu, Q. Urban-rural integration in the earthquake zone: Sichuan's post-disaster reconstruction and the expansion of the Chengdu Metropole. Pac. Aff. 2011, 84, 495-523. [CrossRef]

21. Jia, S.Q.; Wang, C.X.; Li, Y.F.; Zhang, F.; Liu, W. The urbanization efficiency in Chengdu City: An estimation based on a three-stage DEA model. Phys. Chem. Earth Parts A/B/C 2017, 101, 59-69. [CrossRef]

22. Schneider, A.; Seto, K.C.; Webster, D.R. Urban growth in Chengdu, Western China: Application of remote sensing to assess planning and policy outcomes. Environ. Plan. B Plan. Des. 2005, 32, 323-345. [CrossRef]

23. Webster, D.R.; Cai, J.M.; Muller, L.; Luo, B.Y. Peri-Urbanization in Chengdu, Western China: From "Third Line" to Market Dynamics; Asia-Pacific Research Center, Stanford University Stanford: Stanford, CA, USA, 2004; pp. 94306-96055. Available online: https://fsi.stanford.edu/sites/default/files/Webster_etal_Chengdu_2004. pdf (accessed on 1 March 2020).

24. Liu, C.C. An urbanism theory for Chengdu: Criteria towards Advancing an Alternative Urban Development Model for Central Chinese Cities. Master's Thesis, Graduate College of the University of Illinois at Urbana-Champaign, Urbana, IL, USA, 2014.

25. Tippins, J.L. Planning for Resilience: A Proposed Landscape Evaluation for Redevelopment Planning in the limpan Landscape. Master's Thesis, University of Washington, Seattle, WA, USA, 2014.

26. Sun, D.J.; Chen, Q.B.; Hu, T.X.; Liu, G.L.; Sun, D.Y.; Luo, Q.G. Community types and diversity of farmhouse forest in Western Sichuan Province. J. Sichuan Agric. Univ. 2011, 29, 22-28. (In Chinese)

27. Tao, J.; Su, X.Y.; Li, N.; Wang, J.; Chen, Q.B. Research on the eco-wisdom of linpan in Chengdu Plain. In International Conference on Arts, Design and Contemporary Education (ICADCE 2016); Atlantis Science Co. Ltd.: Beijing, China, 2016; pp. 681-684. Available online: https://www.atlantis-press.com/proceedings/icadce16/25858321 (accessed on 1 March 2020).

28. Kiehl, J. Lessons from the Earth's past. Science 2011, 331, 158-159. [CrossRef] 
29. Tran, L.; Brown, K. The importance of ecosystem services to small holder farmers in climate change adaptation: Learning from an ecosystem-based adaptation pilot in Vietnam. Agrofor. Syst. 2019, 93, 1949-1960. [CrossRef]

30. Vignola, R.; Harvey, C.A.; Bautista-Solis, P.; Avelino, J.; Rapidel, B.; Donatti, C.; Martinez, R. Ecosystem-based adaptation for smallholder farmers: Definitions, opportunities and constraints. Agric. Ecosyst. Environ. 2015, 211, 126-132. [CrossRef]

31. Diaz, S.; Lavorel, S.; Bello, F.D.; Quetier, F.; Grigulis, K. Incorporating plant functional diversity effects in ecosystem service assessments. Proc. Natl. Acad. Sci. USA 2007, 104, 20684-20689. [CrossRef] [PubMed]

32. Luck, G.W.; Harrington, R.; Harrison, P.A.; Kremen, C.; Berry, P. Quantifying the Contribution of Organisms to the Provision of Ecosystem Services. BioScience 2009, 59, 223-235. [CrossRef]

33. de Bello, F.; Lavorel, S.; Diaz, S.; Harrington, R.; Cornelissen, J.H.C. Towards an assessment of multiple ecosystem processes and services via functional traits. Biodivers. Conserv. 2010, 19, 2873-2893. [CrossRef]

34. Garcia-Lorente, M.; Martin-Lopez, B.; Diaz, S.; Montes, C. Can ecosystem properties be fully translated into service values?? An economic valuation of aquatic plant services. Ecol. Appl. 2011, 21, 3083-3103. [CrossRef]

35. TEEB. The Economics of Ecosystems and Biodiversity: Ecological and Economic Foundations; Earthscan: London, UK, 2010; pp. 1-410.

36. Vihervaara, P.; Ronka, M.; Walls, M. Trends in Ecosystem Service Research: Early Steps and Current Drivers. Ambio 2010, 39, 314-324. [CrossRef]

37. Schaich, H.; Bieling, C.; Plieninger, T. Linking ecosystem services with cultural landscape research. GAIA 2010, 19, 269-277. [CrossRef]

38. Martin-Lopez, B.; Iniesta-Arandia, I.; Garcia-Llorente, M.; Palomo, I.; Casado-Arzuaga, I.; Del Amo, D.; Gomez-Baggethun, E.; Oteros-Rozas, E.; Palacios-Agundez, I.; Willaarts, B.; et al. Uncovering ecosystem service bundles through social preferences. PLOS ONE 2012, 7, e38970. [CrossRef]

39. Chan, K.M.A.; Satterfield, T.; Goldstein, J. Rethinking ecosystem services to better address and navigate cultural values. Ecol. Econ. 2012, 74, 8-18. [CrossRef]

40. Hou, Y.; Müller, F.; Li, B.; Kroll, F. Urban-rural gradients of ecosystem services and the linkages with socioeconomics. Landsc. Online 2015, 39, 1-31. [CrossRef]

41. United Nations. Sustainable Development Goals, Goal 11: Make Cities Inclusive, Safe, Resilient and Sustainable. Available online: https://www.un.org/sustainabledevelopment/cities/ (accessed on 25 February 2020).

42. Haase, D.; Larondelle, N.; Andersson, E.; Artmann, M.; Borgström, S.; Breuste, J.; Elmqvist, T. A quantitative review of urban ecosystem service assessments: Concepts, models, and implementation. Ambio 2014, 43, 413-433. [CrossRef]

43. Liu, Q.; Wang, Y.K.; Guo, Y.M.; Peng, P.H. Research progress of linpan in Chengdu Plain. Chin. Agric. Sci. Bull. 2017, 33, 150-156. (In Chinese)

44. Liu, Q.; Xu, P.; Yan, K.; Guo, Y.M. Pollination Services from Insects in Homegardens in the Chengdu Plain will be Confronted with Crises. Sustainability 2019, 11, 2169. [CrossRef]

45. Millennium Ecosystem Assessment. Ecosystems and Human Well-being: A Framework for Assessment; Island Press: Washington, DC, USA, 2003.

46. ArcGIS (Desktop, Engine) 10.6.1. Available online: https://support.esri.com/en/products/desktop/arcgisdesktop/arcmap/10-6 (accessed on 16 April 2020).

47. FRAGSTATS: Spatial Pattern Analysis Program for Categorical Maps. Available online: https://www.umass. edu/landeco/research/fragstats/downloads/fragstats_downloads.html (accessed on 16 April 2020).

48. Chengdu Academy of Urban Planning and Designing. Protection and Utilization Plan of Chuanxi Linpan in Chengdu; Urban and Rural Construction Commission of Chengdu: Chengdu, China, 2014. (In Chinese)

49. Duan, P.; Liu, T.H. Linpan (Wooded Lot)—The Ecological Homeland of Shu Culture; Sichuan Science and Technology Press: Chengdu, China, 2004. (In Chinese)

50. Lin, G.X. Modernizing trend of linpan settlements in Chengdu Plain. J. Southwest Agric. Univ. (Soc. Sci.) 2011, 9, 5-9. (In Chinese)

51. Li, S.Q. Conceptual Study on the Construction of Rural Town in Chengdu; Publishing House of Southwest Jiaotong University: Chengdu, China, 2009; pp. 50-54. (In Chinese)

52. Chen, Q.B. Study on the Protection and Development of Linpan Landscape in West Sichuan; China Publishing House of Forestry: Beijing, China, 2011; pp. 22-24. (In Chinese) 
53. Zhang, Y. Study on Protection and Development of Linpan System in West Sichuan. Master's Thesis, Southwest Jiaotong University, Chengdu, China, 2008. (In Chinese).

54. Fang, Z.R. History of linpan culture in west Sichuan. J. Chengdu Univ. (Soc. Sci.) 2011, 5, 45-49. (In Chinese)

55. Wang, F.Y.; Chen, Y.H. Exploration of linpan settlement planning in west Sichuan and the revelation for the new rural community. Study Modem City 2013, 8, 25-29. (In Chinese)

56. Pu, D.H.; Liu, M.L.; Zong, H. Research on winter microclimate of linpan in western Sichuan Province. J. Hum. Settl. West China 2016, 31, 107-111. (In Chinese)

57. Yuan, L. Innovation in Ecological Area-Indigenous and Local Knowledge about Settlements in Dujiangyan Watershed and Its Modern Value; Publishing House of Construction Industry: Beijing, China, 2018; pp. 1-243.

58. Fang, Z.R.; Li, X.K. Analysis on the cultural value of linpan in west Sichuan. J. West China Univ. (Soc. Sci.) 2011, 30, 26-30. (In Chinese)

59. Fu, Z.W.; Deng, B. The protection and development of linpan cultural landscape in Chengdu Plain under the urbanization-A case of Chongzhou city, Sichuan Province. In Proceedings of the Annual Conference 2014-China Society of Scenery and Landscape (Volume 1); Chinese Society of Landscape Architecture: Beijing, China, 2014; Available online: http://www.cpfd.cnki.com.cn/Article/CPFDTOTAL-ZGFV201409002006.htm (accessed on 23 December 2019). (In Chinese)

60. Fang, Z.R. Study on Limpan Settlement Culture of West Sichuan; Southeast University: Nanjing, China, 2013. (In Chinese)

61. Liu, B.; Mu, J. Plan and design of new rural settlement in considering linpan protection in west Sichuan. Sichuan Archit. Sci. 2012, 38, 252-255. (In Chinese)

62. Guo, Y.M. Study on Spatial-Temporal Variation Characteristics and Driving Forces of Linpan in Chengdu Plain-A Case of Pi County. Master's Thesis, Institute of Mountain Hazards and Environment, Chinese Academy of Sciences, Chengdu, China, 2017.

63. Fan, Y.Z. Study on the Protective Planning and Designing of the Landscape of Chuanxi Linpan. Master's Thesis, Sichuan Agricultural University, Ya-An, China, 2009. (In Chinese).

64. Cai, X.Y. Preliminary analysis on the value of traditional rural building-Exemplified by linpan in west Sichuan. Theory Reform 2009, 4, 151-153. (In Chinese)

65. Costanza, R.; Daly, H.E. Natural capital and sustainable development. Conserv. Biol. 1992, 6, 37-46. [CrossRef]

66. Fisher, B.; Turner, R.K.; Morling, P. Defining and classifying ecosystem services for decision making. Ecol. Econ. 2009, 68, 643-653. [CrossRef]

67. Guedes, J.A. Millets, rice, social complexity, and the spread of agriculture to the Chengdu Plain and southwest China. Rice 2011, 4, 104-113. [CrossRef]

68. Wang, K.; Li, H.; Zhang, C.; Lang, M.; Zhong, W.T.; Yang, S.; Sun, J.; Wang, Q. Analysis on current situation of grain production in Chengdu. Sichuan Agric. Technol. 2018, 3, 2-3.

69. Statistic Bureau of Chengdu. Chengdu Statistical Yearbook; China Statistics Press: Beijing, China, 2019; pp. 1-335.

70. Chen, H.; Zhu, Q.; Peng, C.; Wu, N.; Wang, Y.; Fang, X.; Jiang, H.; Xiang, W.; Chang, J.; Deng, X.; et al. Methane emissions from rice paddies natural wetlands, and lakes in China: Synthesis and new estimate. Glob. Chang. Biol. 2013, 19, 19-32. [CrossRef]

71. IPBES. Summary for Policymakers of the Assessment Report of the Intergovernmental Science-Policy Platform on Biodiversity and Ecosystem Services on Pollinators, Pollination and Food Production; Secretariat of the IPBES: Bonn, Germany, 2016; pp. 1-36.

72. Du, S.K.; Zhang, X.J. Historic Economy of Chang and Zhen in Sichuan; Press of Sichuan Academy of Social Science: Chengdu, China, 1986; Volume 1.

73. Skinner, G.W. Marketing and social structure in rural China (Part 1). J. Asian Stud. 1964, 24, 3-43. [CrossRef]

74. Li, L.; Zhang, Y.J. Rural ecotourism: An effective way of maintaining indigenous character in rapidly urbanizing rural areas: A case study of Five Golden Flowers in Chengdu, China. J. Resour. Ecol. 2017, 8, 485-493.

75. Wang, Y.; Liu, J.; Xue, H.T.; Tan, Z.B. Rural plan implementation based on land property right innovation: A case study on Qinggangshu Village in Chengdu. Dev. Small Cities Towns 2018, 1, 26-32.

76. Xu, S. Study on Plant Diversity of Limpan in West Sichuan. Master's Thesis, Sichuan Agriculture University, Ya'an, China, 2010. 
77. DeFries, R.S.; Foley, J.A.; Asner, G.P. Land-use choices: Balancing human needs and ecosystem function. Front. Ecol. Environ. 2004, 2, 249-257. [CrossRef]

78. Rodriguez, J.J.; Beard, T.D.J.; Bennett, E.M.; Cumming, G.S.; Cork, S.J. Trade-offs across space, time, and ecosystem services. Ecol. Soc. 2006, 11, 28. [CrossRef]

79. Fabbricatti, K.; Biancamano, P.F. Circular economy and resilience thinking for historic urban landscape regeneration: The case of Torre Annumziata, Naples. Sustainability 2019, 11, 3391. [CrossRef]

80. De Groot, R.S.; Alkemade, R.; Braat, L.; Hein, L.; Willemen, L. Challenges in integrating the concept of ecosystem services and values in landscape planning, management and decision making. Ecol. Complex 2010, 7, 260-272. [CrossRef]

81. Ghazoul, J. Recognising the complexities of ecosystem management and the ecosystem service concept. GAIA 2007, 16, 215-221. [CrossRef]

82. Luck, M.A.; Jenerette, G.D.; Wu, J.G.; Grimm, N.B. The urban funnel model and the spatially heterogeneous ecological footprint. Ecosystems 2001, 4, 4782-4796. [CrossRef]

(C) 2020 by the authors. Licensee MDPI, Basel, Switzerland. This article is an open access article distributed under the terms and conditions of the Creative Commons Attribution (CC BY) license (http://creativecommons.org/licenses/by/4.0/). 